\title{
Medical geneticists in the 21st century
}

Charles J. Epstein, MD

In this, my third and last presidential address, I want to present to you my own views about some of the broad issues that concern the state of clinical medical genetics-more specifically, the state of clinical medical geneticists. What I have to say today is entirely personal and unofficial and should not be taken as representing the position of the College.

When I started out over forty years ago in medical genetics, it was essentially a cottage industry that generally operated, it may surprise many of you to know, out of departments of medicine in academic medical centers. This made sense, because most of the self-declared medical geneticists of the time, if they were physicians-and not all were-were internists. The disorders they dealt with were primarily either monogenic, with a heavy biochemical or hematological slant, or chromosomal. Then, with the rise of dysmorphology as a discipline and the advent of prenatal diagnosis, departments of pediatrics and, to a lesser degree, of obstetrics and gynecology, became the preferred homes for medical genetics and medical geneticists.

I used the term "self-declared medical geneticists" a moment ago to make the point that this was a mantle that those with a serious interest in medical genetics placed upon themselves, nearly always over and above a more accepted and officially recognized title such as internist, pediatrician, obstetrician, neurologist, or whatever. With time, however, this did not seem to be sufficient to confer the desired degree of legitimacy upon the practitioners of medical genetics; so, starting in the early 1980s, a certifying board was created, training programs were accredited, examinations were given, and certificates testifying to competence were issued. But even this was not enough in the eyes of organized medicine, because those in charge referred to the American Board of Medical Genetics with the pejorative term "self-designated board," in the same class as the American Boards of Chelation Therapy and of Holistic Medicine. However, about fifteen years ago, with the opening of what, I can assure you, was a very small window of opportunity—small both temporally and conceptually, the final push for true legitimacy was made, and the Liaison Committee for Specialty Boards, one of the Byzantine committees in the netherworld of organized medicine, accepted the premise that the intellectual content of medical genetics was sufficiently new and different and independent to allow it to

\footnotetext{
The ACMG presidential address was presented March 17, 2004 at the 2005 Annual Clinical Meeting of the American College of Medical Genetics, Grapevine (Dallas), Texas.

From the Department of Pediatrics, University of California, San Francisco, California.

Charles Epstein, MD, Department of Pediatrics, U585L, University of California, 533 Parnassus, San Francisco, CA.
}

DOI: 10.1097/01.GIM.0000170771.50414.79 stand alone, separate from all other specialties-indeed, to transcend the other specialties. And therefore, to everyone's great surprise, not the least our own, but to the dismay of some, the American Board of Medical Genetics became the twentyfourth, smallest, and last primary specialty board to be admitted into the sacrosanct American Board of Medical Specialties. And, to put this into perspective, medical genetics at the time was rather primitive by current standards. After all, it was before the time that the genome project really got going, before microarrays and comparative genomic hybridization and SNPs, and before McKusick's catalog became OMIM and just after Stanbury became Scriver.

However, this success did not come without significant costs, the major one being that although the American Board of Medical Genetics was permitted to continue to certify and accredit training programs for medical geneticists who were not physicians, which was almost without precedent, it was prohibited from doing the same for masters degree-level genetic counselors. This separation of the counselors from the clinical and laboratory geneticists created a rift within the medical genetics community that has never completely healed and may, I fear, actually be becoming wider. Nevertheless, with acceptance of Medical Genetics into the American Board of Medical Specialties came the final trappings of a real clinical specialty - this College, the Residency Review Committee, a seat in the councils of the AMA, and membership in the Council of Academic Societies. Medical genetics had truly arrived.

So, where are we now? To be more specific, where are the physician-clinical medical geneticists now? It is, of course, obvious to you that I am not using the term "where" in a geographical sense, but there is one bit of geography that does deserve comment. Clinical medical genetics is perhaps unique among all of the medical specialties in that, by virtue of its history, it is practiced principally in or in close affiliation with academic medical centers. Although there are medical geneticists working in various types of multidisciplinary health care organizations and even some in private practice situations, the overall affiliations and orientation of the majority are academic, a fact that is certainly reflected in the composition of the College and of its officers and committees. This reality needs to be kept in mind when we discuss both the present and the future of medical genetics and geneticists.

Returning then to the question of where, in the general sense, medical geneticists are now, all of you know that there has been an alarming decrease in the number of people entering medical genetics training programs that has resulted in a decline in the number of clinical geneticists becoming board certified. In contrast to genetic counselors, our numbers are increasing only very slowly and threaten to decrease as the older 
generation of medical geneticists, those certified in the 1980s, begins to retire. Furthermore, many of us are concerned, dissatisfied, apprehensive, troubled-use any adjective you like-about the general state and status of our profession and often about our own situations as geneticists. Some are even wondering whether, in this time of the vast expansion in genetic research and public interest in genetics, clinical medical genetics can or, indeed, should survive as an independent specialty. Perhaps, it has been suggested, we should go back to the "good old days," when clinical genetics was a de facto, if not a bona fide, subspecialty of pediatrics. How did we get ourselves in this mess?

It is, of course, always tempting to look outward for explanations- to the extrinsic factors and pressures that have affected our ability to practice - and there are many. Economic and organizational factors over which we as individuals or as a group have little or no control govern every aspect of the practice of medicine. Primary care practitioners and other specialists are being urged to incorporate genetics into their practice. Genetic counselors are bypassing medical geneticists and teaming up with oncologists and other specialists to offer genetic counseling. Other specialists do not recognize or feel the need to refer patients to medical geneticists. Genetic testing and genetic counseling are being offered on the internet, both direct-to-consumer and direct to physician. And I could go on and on. There is a greater or lesser degree of truth in all of these assertions, and they need to be dealt with — but not by me right now.

However, lest I be accused of ignoring reality, I certainly do acknowledge that economic considerations undoubtedly play a major role-perhaps even the major role-in dissuading people from entering medical genetics. Given the generally poor reimbursement-you could even say unusually poor reimbursement-for clinical genetic services and the relative paucity of positions, both of which lead to a sense of considerable instability, a prospective trainee indeed has to be unusually committed to genetics as a field, especially if his or her interests are more on the clinical than on the research side. Unfortunately, despite our efforts to craft better CPT codes and to be more creative in seeking reimbursement, the financial problems that plague us are similar to those affecting many of the so-called cognitive specialties, and the solutions are not really in our own hands. Many, if not most, academic-based clinical geneticists have been able to survive only by relying on some combination of clinical income, nonclinical academic salary, research grants and contracts, laboratory-based income, and/or subsidies from their clinical departments, which require their expertise in dysmorphology or metabolic diseases. There is no way that they can do it based on clinical income alone, at least as medical genetics is now conceptualized and practiced. There have been many discussions and models advanced in the past few years about how medical genetics as currently conceived is and might be practiced, and it is regrettable, but not surprising, given the countervailing forces, that they have not led to significant improvements in the situation. That does not mean that we should not keep trying- indeed we should — but perhaps it is time to look at how medical genetics is conceptualized by us and the world around us.

So let me now turn and look inward to what I regard as a very real problem that is confronting us: we are not really sure who we are and where we ought to fit into the system. There seem to be almost as many ways of practicing medical genetics as there are medical geneticists, and if we are not sure of what we are doing ourselves, how can we expect anyone else to be? A few minutes ago in my brief historical overview, I spoke of medical genetics becoming a primary specialty of medicine, one of twenty-four separate and parallel primary specialties. What does this mean? To me, this means that medical genetics is a specialty that is beholden to no other-not to internal medicine, not to obstetrics, and certainly not to pediatrics. Despite our modest numbers, medical genetics is not a subspecialty of anything, our board is not a sub-board, and our RRC is equal to all the others. And yet, despite the imprimatur we received from the American Board of Medical Specialties and all that has happened in genetics since we received it, many of us seem to doubt that medical genetics really is a primary specialty with something unique to offer. The pervasiveness of this feeling really came home to me with great force at the Banbury Conference-which I assume you all know was held last October at Cold Spring Harbor to discuss the training of physicians in medical genetics - when the participants- the representatives of organized medical genetics, your representatives-were queried as to whether they regarded medical genetics as a primary specialty. Most everyone seemed to be taken aback by the question, and for the longest time you could hear a pin drop. Then the discussion really began. What does it mean to be a primary specialty? What difference would it make? Is not genetics really a subspecialty of pediatrics? Why should we care? I could not help but be reminded at the time of the aphorism uttered by the world's most famous possum, Pogo: "We have met the enemy and he is us." Nevertheless, the outcome of this discussion, which is enunciated in the first of the three principles contained in the report of the Banbury Conference, was that the people at the conference agreed that medical genetics is truly a primary specialty of medicine: one that can really stand on its own.

Why was it so hard at Banbury, at least initially, and, I dare say, for at least some of you now, to embrace this premise? In asking this, I am not interested in playing semantic games with the term "primary specialty." After all, the American Board of Medical Specialties says that we are one, no matter what anyone thinks. The real issue is with what the term connotes, and to me it is that medical genetics is a specialty that has sufficient merit to stand on its own and, if one should so desire, to be practiced on its own. To me, it also means that being a medical geneticist is at least as important and valuable and worthy of recognition as being any other type of specialist. Why do so many have trouble with this concept? Two obvious and related reasons that come immediately to mind are, first, that virtually all clinical geneticists are certified in another specialty and, second, that those in medical centers, whether academic or not, generally operate within the clinical department repre- 
sented by their second certification, this being most often pediatrics. Only in rare instances do geneticists operate within departments of human or medical genetics. Therefore, although they (by which I mean we) might spend most or perhaps all of their time practicing genetics, they are still regarded by the outside world as being pediatricians or internists or obstetricians or family practitioners, with genetics being their subspecialty. The orientation to the nongenetics specialty is, of course, reinforced by the fact that entry into most clinical genetics training programs requires two years of training in another primary specialty, and it seems only natural and prudent, for all the obvious economic and organizational reasons, for trainees to stay on for another year and become certified in that specialty. It is conceivable that the joint training programs that exist or are being developed between medical genetics and pediatrics, internal medicine, or maternal and fetal medicine, which could certainly be expanded to other specialties, could go some way toward bringing genetics psychologically up to par with the other specialties, but I do not really know.

Another reason that it seems difficult for many, especially outside the field, to view medical genetics as something unique is that everyone seems to be getting into the act and is either doing genetics or is being told that he or she ought to be. How ironic it is that the successful dissemination of the message that genetics is really important in medicine is threatening - or at least I fear that it is threatening - to undermine medical genetics as a specialty. After all, if genetics is intrinsic to all parts of medicine, as we ourselves have been preaching, what is it that makes our discipline so special? This is a critical question, and I shall come back to it in a few minutes.

The problem of self-perception also has its roots in the content of our training programs as specified by the Board and the Residency Review Committee. Starting over thirty years ago, there began what has been termed a "pediatricization" of medical genetics, and medical genetics has remained heavily pediatric in orientation ever since. As a result, the major emphases in most training programs and in the board examinations have been on congenital malformations and dysmorphology, on a variety of mendelian disorders that mainly affect children, and on newborn screening and carrier detection. With the exception of the inborn errors of metabolism, which constitutes the only area in which therapy plays a significant role, all of the areas we emphasize are largely passive and involve principally testing, diagnosis, and counseling for which we get paid very little. All of these areas are important and necessary, and, in fact, it is our expertise in just this corner of clinical genetics that made medical geneticists unique in the past. There would be absolutely nothing wrong with this if things had stopped where they were thirty years ago. But they have not: medical genetics is not just a subspecialty of pediatrics, and the science has moved on and continues to move on.

So, here's the rub. The prevailing philosophy of training and practice is still largely pediatric in nature, but genetics in medicine in the broad sense no longer is. I think that you all know what has changed. The notion of what is genetic has vastly expanded, and the message that virtually all human diseases and responses to therapy are the product of both genetic and environmental factors has finally really taken hold. The age of complex traits has now arrived with a vengeance. Genetic epidemiologists and biotech companies are hard at work trying to identify mutations and variants-it's becoming difficult to know what to call them-that influence susceptibility to disease and the efficacy and toxicity of drugs. There are two anticipated outcomes to this research: a better understanding of disease pathogenesis, which, it is hoped, will lead to the design of new therapeutic agents, and the development of genetic tests to predict who will be at risk for what. It is, of course, the genetic testing that concerns us directly, but we still have not figured out what we should do about it. Should we cede it to the primary care providers and to other specialists and to genetic counselors, as we have already done to a large extent with cancer risk testing, or should genetic testing and more comprehensive risk assessment for complex traits come within the purview of medical genetics? My belief is the latter. Genetics, which is within our scope of practice, is involved in genetic testing and risk assessment. Therefore, we should be involved, not necessarily as the sole providers-perhaps, not ever as the sole providers-but certainly as an intrinsic part of the process.

If we are to do this, two things will be required of us. The first will be a radical change of mindset, so that our view of what medical genetics is and medical geneticists ought to be doing expands beyond pediatrics to encompass all of medicine and the full range of genetic disease. In plain words, this means that adult or complex trait or common disease genetics-whatever you want to call it—needs to become as important as dysmorphology is and metabolic diseases ought to be. We need to be as comfortable with all of the genetic issues of adults as we are with those of fetuses, infants, and children. Furthermore, with regard to the metabolic diseases, an area that we have always regarded as being important, I would like to point out that here the name of the game is therapy and the role of the medical geneticist is an active rather than a passive one. In fact, to a large extent it is only within the domain of the inborn errors that medical geneticists use the full range of powers available to them as physicians: the power to diagnose, to treat, and to prevent disease. Without trying to be overdramatic, I think that when we think of our roles as geneticists, many of us have forgotten that we really are physicians. Acceptance of this reality may be one of the keys to securing the future of medical genetics.

But, altering the mindset is not the only thing that will need to be done. This attitudinal change will have to be coupled with significant changes in the training of medical geneticists to ensure that they will have the knowledge base to support it. For starters, medical geneticists need to know more genetics and, while they are at it, epidemiology as well. I know what the RRC requirements say about the equivalent of a one-year graduate course in human genetics, but I just do not think that we are teaching our trainees enough genetics, and we are certainly not teaching them enough epidemiology. And, beyond learning the genetics and epidemiology that are required, the trainees 
also need to put together the genetics with the diseases themselves-coronary artery disease, diabetes, obesity, cancer, and psychiatric disorders-and they will have to learn about the pharmacogenetics of the drugs that are being used.

What I am suggesting, then, is a refocusing and rebalancing of the training of medical geneticists. We need to preserve the things that made medical genetics unique in the past-in fact, I think we even need to enhance biochemical genetics, an area in which we have not asserted ourselves sufficiently—and then add in what will be required to make medical genetics continue to be unique in the future. And what will make us unique is not that that we will be delivering all genetic services for all conditions: we assuredly will not. Rather, it is that we will have a comprehensive working knowledge of the applications of genetics to the broad expanse of clinical medicine that will permit us to interact effectively with practitioners of all specialties and with persons seeking genetic advice of all types. This is what will make our specialty distinct from all others and will justify our continued existence as a primary specialty of medicine.

As I have been laying out this personal vision of self-perception and mindset and training, I certainly realize, human nature being what it is, that not everyone will want to or be able to engage in such a broadly based practice of medical genetics and might prefer, even as now, to concentrate on dysmorphology or biochemical genetics or cancer genetics. Perhaps, the range of what I am suggesting might just be too much for any single person to be able to handle alone in a competent manner. Well, that is a matter for discussion, but I believe quite strongly that the range of basic competencies for all medical geneticists needs to be expanded and that the core of training has to be more comprehensive and intensive than it now is.

Can the type of training that I have been speaking about be done in a two-year period? Probably not, and I believe that we need to rethink our approach to the length of medical genetics training. I am not aware of any other primary specialty that expects its trainees to learn everything they need to know in just $11 / 2$ years, as we do in medical genetics if we exclude the six months allowed for research. This is really quite a short time to get everything in, even under the current training guidelines. And, of course, if we look at it just from the perspective of training in medical genetics (and not of the desire of trainees to have a second certification that I discussed earlier), there is nothing sacred about the requirement for two years of prior training in some other specialty. This, presumably, is to give a broad grounding in clinical medicine, but as the rules now stand, the other specialty could as easily be emergency medicine or urology as one of the more conventional specialties, so I am not sure how well this rationale holds up. Furthermore, if we are willing to allow for the possibility of extending the period of training, then we could also contemplate having time for more intensive training in areas of special interest to particular individual training programs and to individual trainees, whatever these areas might be. We really do not have to feel constrained-let me put it more strongly, we should not be constrained - by the training models that we currently have in place. As a primary specialty, we do have the luxury of determining our own course of action.

Some of what I have been saying may sound quite chauvinistic, but I don't really mean it to be. While I do believe in genetics by the geneticists, I am not saying that it should be genetics only by the geneticists. There is just no way that this can or will really happen, nor should it, and I think that it would be highly unwise for us to pursue such a course. To the contrary, I think that it would certainly be in the interest of both the public and medicine in general, as well as in our own interest, to work with the other specialties of clinical medicine, primary care and otherwise, to educate their practitioners in two things: what they, as nongeneticists, can and ought to be doing by themselves, and what we, as geneticists, can and should be doing. Although we can sit back and wait for these specialties to come to us, as some already have to a limited degree, I think that it would be far better for us to become proactive and take the initiative in seeking to work together with them. There are many forms that such interactions could take, ranging from purely educational efforts in meetings and courses directed at the general membership of these specialty groups to the much more intensive genetic education, in circumscribed areas, of limited numbers of other specialists through such vehicles as targeted fellowships and joint forms of certification.

In suggesting that we become proactive with other specialties, I am not speaking about altruism, although I dare say that medical geneticists as a group are probably more altruistic than most and seem to be willing to share what they know for free. Rather, I believe that, in the long run, we shall, as the old saying goes, catch more flies with honey than with vinegar. It is not a matter of continuing to give away what we know for free, but rather of seeking to develop a set of working relationships that will enhance the ability of medical geneticists to be a vital part of medicine. Is there a danger that these forms of educational outreach will not have the desired effect and will instead lead to increased competition and erosion of turf and to further marginalization of medical genetics? Anything is possible, of course, but what are our real alternatives? Trying to go it alone and compete head-on will not work. After all, patients rarely come to see geneticists right off the street, and it is their primary care providers and more conventional specialists that have the first crack at them. We need to evolve a system of interaction and referral that works to our best advantage.

Although my entire talk has been cast in terms of our relationships with other physician groups, I am certainly not unmindful of the fact that we already have a very strong relationship with the genetic counselors about which, you may recall, I expressed some concern. At this point all I can say is that we have to be very careful, in whatever we do, to maintain and enhance the relationship between counselors and medical geneticists that has existed since the profession of genetic counseling was born and has done so much to make clinical genetics as effective as it is today.

I know that I have ranged over a great deal of territory and have given you lots of personal opinions, so I would like to put 
a point on all of it and conclude by posing just two questions: Should medical genetics continue to be a primary specialty of medicine? And, if so, what will it take to make it viable?

I have told you where I stand, and I would only add that for me it would be the bitterest of ironies if our enterprise should fail just at the time when we are seeing the flowering of the applications of human genetics to medicine. However, much more important than where I stand is where all of you stand. The future of your profession is in your hands, and I urge you to move forward. 